\title{
O SER DO PROFISSIONAL DE LAZER E O PROCESSO AUTOFORMATIVO
}

\author{
Sonia Cristina Ferreira Maia ${ }^{1}$ e Kátia Brandão Cavalcanti ${ }^{2}$ \\ ${ }^{1}$ Professora do Centro Federal de Educação Tecnológica do Rio Grande do Norte \\ (CEFET-RN); Mestre em Educação; sonia@cefetrn.br \\ ${ }^{2}$ Professora da Universidade Federal do Rio Grande do Norte (UFRN); Doutora em \\ Educação
}

Recebido em agosto/2004 e Aceito em dezembro/2004

\section{RESUMO}

O trabalho refere-se a uma pesquisa de abordagem etnometodológica com observação participante, ressaltando a estruturação dos saberes construídos pelos profissionais que se encontram em processo de crescimento na sua ação prática estruturada. O grupo investigado é constituído por alunos do Curso de Tecnologia em Lazer e Qualidade de Vida do CEFET-RN. Tendo como disciplinas de suporte: a) Lazer, Corpo e Sociedade; b) Trabalho de Conclusão de Curso I (TCC I). Com objetivo de analisar o processo de construção de saberes do Ser por profissionais metamotivados para o autodesenvolvimento como ser humano. Dessa forma, a relevância em investigar a ousadia do profissional do lazer que está buscando transpor essas barreiras tradicionais, num modelo educacional que não é lido nas Escolas Brasileiras. Os alunos, que são participantes da pesquisa aderiram a esse projeto de discussão da prática por compreenderem a relevância da construção de saberes a partir das questões do cotidiano como situações problematizadoras refletindo o momento e estando a procura de uma interpretação para aquilo que é vivenciado. Esse momento e vivenciado na disciplina de TCC I através de temas sobre a autoformação do profissional de lazer.

Palavras chaves: Lazer - Autoformação - Ser - Profissional. 


\section{O SER DO PROFISSIONAL DE LAZER E O PROCESSO AUTOFORMATIVO}

\section{INTRODUÇÃO}

O mercado de trabalho do profissional de lazer exige mão-de-obra qualificada, antenada com as transformações sociais ocorridas no mundo do trabalho, como também um profissional que visualize o potencial da vivência do lazer como um aspecto significativo da vida cotidiana do homem, inserido no contexto social real e numa dinâmica de vida que coloca em permanente processo de crescimento pessoal e social.

O campo de trabalho do profissional do lazer exige uma sólida qualificação com todos os adjetivos, embora o mercado de trabalho negligencie tais critérios. Porém, faz-se necessário extrapolar os muros da formação acadêmica e trilhar pela autoformação, buscando nesse processo desnudar a formação do ser humano na construção dos saberes cotidianos. Como relata Moraes (1997, p.212),

O desenvolvimento humano depende de nossa capacidade de reflexão, do aprimoramento das habilidades de pensar e saber, o que significa saber que se sabe. É aquele ser que pensa, que sabe o que quer, que escolhe e decide a sua experiência diante das possibilidades que se apresentam. E o ser que constrói a sua própria identidade, a partir de sua liberdade e autonomia para tornar-se sujeito.

De acordo com Moraes (1997), uma nova educação para a era das relações requer que a inteligência, a consciência e o pensamento, assim como o conhecimento, seja visto, como estando em processo, em continuidade, e que o produto resultante de cada uma dessas atividades nunca estará completamente pronto e acabado, mas num movimento permanente de "vir a ser", assim como o movimento das marés constituído de ondas de reflexão que se desdobram em ações, e que se dobram e se concretizam em novos processos de reflexão sobre as ações desenvolvidas. É um movimento recursivo de reflexão na ação e de reflexão sobre a ação. Requer a reflexão crítica sobre a práxis histórica.

Em conformidade com a construção dos saberes pelo ser, Petraglia (1995) levanos a refletir sobre o pensamento Moriniano, no compromisso de desfazer os nós do preconceito da teoria do conhecimento. Sugerindo uma reflexão do ser e do saber pela via da complexidade. Na afirmação de Morin, citado por Petraglia, (1995, p. 42):

“O regresso ao começo não é um círculo vicioso se a viagem, como hoje a palavra trip indica, significa experiência, donde se volta mudado. Então, talvez tenhamos podido aprender a aprender aprendendo. Então, o círculo terá podido transformar-se numa espiral onde o regresso ao começo é, precisamente, aquilo que afasta do começo”.

Essa viagem de ida e volta para aperfeiçoar o aprendido, leva-nos a refletir sobre nós mesmos e a nossa participação na sociedade aprendente e permite a compreensão do inacabado no ser. Dessa forma, busca-se constantemente uma autoformação que ajuda a construir o caminho dessa viagem. 
Como destaca Borges (1998), os saberes oriundos da experiência do profissional do lazer, que é elemento essencial na sua autoformação como também a formação, não pode ser ignorados na constituição dos currículos. Mesmo porque a experiência é um saber próprio do profissional. É o saber construído na relação/integração do sujeito com a pluralidade dos saberes disponíveis. Nesse contexto, problematiza-se as reflexões traçadas na disciplina Lazer, Corpo e Sociedade que tem como competência identificar o embasamento teórico sobre o conhecimento que trata o corpo, articulando as relações existentes com o lazer no processo de humanização e a sociedade moderna, privilegiando os entornos sociais. Ainda nessa problematização, ressalta-se o desembocar das reflexões feitas pelos alunos, na disciplina de Trabalho de Conclusão de Curso I (TCC I).

\section{OBJETIVO DO ESTUDO}

Numa visão ecológica de sociedade contemporânea, destaca-se a importância do contexto e da cultura e, ao mesmo tempo, mostra "que somos criaturas de nossa cultura, assim como somos criaturas de nosso cérebro” (Gardner, 1994, p. 37), reconhecendo os papéis que desempenham no desenvolvimento das inteligências humanas, nas estruturas mentais, na evolução das competências intelectuais e, consequentemente, nos desenvolvimentos individual e grupal. Nesse contexto, posiciona-se o profissional do lazer nessa conjuntura e que por vezes está atrelado a conceitos impostos socialmente e que precisam ser rompidos para permitir o conhecer para se chegar a uma autonomia, fazendo fluir sua ação prática nessa sociedade, que por ora está carente e sedenta de humanização.

Considerando as reflexões já apresentadas, faz-se a leitura de um profissional capaz de participar efetivamente da vida social e política, assumindo tarefas e responsabilidades que dialoga num mundo interativo e interdependente, impregnado dos instrumentos de sua cultura, utilizando-se para sua emancipação, transformação, libertação e transcendência. Acredita-se que seja dotado de competências fundamentais no sentido de capacitar-se para assumir o comando da própria vida, numa participação direta, efetiva e responsável no viver em sociedade.

Na definição do objeto e objetivos desse estudo foram estabelecidas algumas categorias relevantes para encaminhar os desafios propostos nessa investigação, como: saberes do ser, projeto autoformativo, desafios da prática educativa no lazer e o profissional do lazer metamotivados para o seu autodesenvolvimento como ser humano.

Desse modo, no intuito de contribuir com um debate argumentativo sobre a autoformação do ser no campo do lazer, é que formulam-se os seguintes objetivos: Analisar o processo de construção de saberes do ser por profissionais de lazer metamotivados para o autodesenvolvimento de sua corporeidade; Construir de forma compartilhada saberes do ser com profissionais do lazer metamotivados para o seu autodesenvolvimento, a partir dos desafios da prática educativa no lazer que impulsionam o seu projeto autoformativo.

\section{JUSTIFICATIVA}

O indivíduo constrói o conhecimento através de interações que ocorrem entre a cultura e o pensamento e, dessa forma resgata a visão de contexto retratada por Morin 
(2003), revelando que os indivíduos são o que são dentro de determinados contextos, podendo e devendo ser compreendidos a partir de suas conexões e de suas relações com a sua realidade contextual. Isso implica em que a Educação/Estado/Sociedade promova o respeito às diferenças, à diversidade entre os seres, às variações culturais e aos diferentes processos de desenvolvimento humano. Ressalta-se nesse processo alguns aspectos relevantes, dentre eles a interconectividade dos problemas educacionais e a reintegração do sujeito no processo de construção do conhecimento, sendo este algo que está sempre em processo de vir-a-ser. Amplia-se ainda a compreensão ao esclarecer a existência de transitoriedade, da criatividade presente nos processos da natureza e sua importância para a evolução da humanidade.

De um ser pentasensorial evoluí-se para um ser humano multidimensional, não mais limitado pela percepção dos cinco sentidos, nos quais as intuições, as emoções e os sentimentos passaram também a integrar o processo de construção do conhecimento, permitindo uma compreensão mais clara da própria natureza humana. De uma visão de mundo fragmentada, de uma coleção de coisas separadas, o mundo passou a ser compreendido como uma rede de relações, um universo relacional, em constante holomovimento, no qual nada é definitivo e tudo é apenas provável. De um conhecimento visto sob uma perspectiva estática, ou seja, de um conhecimento-estado, passa-se para compreensão do conhecimento-processo, o que revoluciona a compreensão a respeito do que significa desenvolvimento individual.

Nesse sentido, faz-se urgente o pensamento articulado, antenado com a realidade exposta. É o pensar possibilidades de intervenções que faz a diferença em nossas relações, seja no trabalho, na escola, na família, com seus pares. É permitir a inovação ou não em seu contexto. Dessa forma, a relevância em investigar a ousadia do profissional do lazer que está buscando transpor essas barreiras tradicionais, entregando-se, permitindo-se, alargando-se e intervindo-se num modelo educacional que não é lido nas escolas brasileiras. Aventurar-se nessa perspectiva de conhecimento é entende-lo como uma via de várias transversais, com as quais pode-se dialogar com outras realidades, outros mundos. São esses ambientes que devem ser permitidos e nos permitir, também. É esse ambiente complexo que se pode vivenciar o multidimensionalismo do conhecimento.

Num ambiente complexo, interrogar o que está posto possibilita uma reflexão para o que se quer conhecer, como o oxigênio de qualquer proposto de conhecimento. Faz-se necessário no cenário educacional no qual o conhecimento interroga o conhecimento, que deverá estar sendo aprendido, em seu contexto historicamente situado. Porém, refletir sobre o exposto para se conhecer verdades tem que se permitir o olhar para metapontos de vista, ou seja, fazer a leitura também do que está além de si e em si mesmo.

Dominar a própria linguagem significa também saber questionar, discutir, expressar dúvidas, ser capaz de compreender a realidade da forma como ela se apresenta, participando como um ser criativo e crítico, capaz de manejar e expressar o conhecimento usando os códigos de diferentes linguagens. Numa sociedade de informações, as habilidades de comunicar e negociar são condições de sobrevivência, pois as relações sociais solicitam, mais do que nunca, interações entre as pessoas. Requer também capacidade de resolver problemas, de síntese, de tomada de decisões, bem como a habilidade de gerar conhecimento novo ao longo da vida, levá-lo a aprender a aprender, a aprender a pensar, aprender a ser. 
Assim, compreender o ser que se impulsiona a aprender a pensar, é um retorno significante a sociedade, tendo em vista que um dos grandes problemas da educação atual é que as instituições educativas têm dificuldades para ajudar seus alunos a aprender a pensar e aprender a aprender através do estabelecimento de relações e conexões, mesmo sem utilizar as novas tecnologias informacionais. Com o surgimento desses novos instrumentos, as coisas se complicam ainda mais. Isto porque temos dificuldades de questionar o arcaico, processos de construção do conhecimento, de aceitar e propor modificações nas estruturas escolares, de expandir a escola, de superar as barreiras existentes entre aluno e professor, escola e comunidade, escola e escola. Todos esses aspectos requerem a diversificação dos espaços do conhecimento, dos processos, das metodologias, pressupondo a expansão das instituições educativas em direção à comunidade, a aceleração de todos esses processos para que possamos resgatar milhares de crianças, adolescentes e adultos impedidos de se posicionarem diante da vida como seres históricos, dotados e situados no tempo e no espaço, como indivíduos capazes de construírem a sua própria identidade, de crescerem e aprenderem ao longo da vida.

Sendo assim, aventuro-me a investigar sobre a autoformação do educador profissional do lazer, mergulhando nas profundezas do seu ser, que está sempre em processo de crescimento, a partir do fenômeno da corporeidade, na qual, estão implícitos saberes acumulados nas experiências vividas.

\section{METODOLOGIA}

Na abordagem etnometodológica, ressalta a estruturação dos saberes construídos por esses profissionais que se encontram em processo de crescimento e sua aplicação no contexto concreto de sua ação prática estruturada, os quais devem possuir um repertório de rotinas de sua ação.

A abordagem etnometodológica busca evidenciar a relação subjetiva que o profissional estabelece com as suas diversas interfaces de seu trabalho e como acontece a intervenção na constituição dos saberes no exercício de sua prática profissional que vão se apoiar na observação participante. Na situação e no contexto serão gerados saberes e práticas que ganharam relevo na análise (Borges, 2001).

O grupo investigado é constituído por alunos do Curso Superior de Tecnologia em Lazer e Qualidade de Vida do Centro Federal de Educação Tecnológica do Rio Grande do Norte (CEFET), 35 egressos no ano de 2002.2. Tendo como disciplinas de suporte a pesquisa: Lazer, Corpo e Sociedade e Trabalho de Conclusão de Curso I (TCC I).

\section{ANÁLISE DOS PRINCIPAIS RESULTADOS FUNDAMENTADOS TEORICAMENTE}

A disciplina de Lazer, Corpo e Sociedade foi ministrada sob a ótica de que todas as abordagens do profissional do lazer devem ter o corpo como referência no fenômeno da corporeidade, favorecendo ambientes de reflexão sobre a construção do Ser nas relações sociais. Num contexto de entendimento histórico da sociedade, desde as sociedades antigas até a contemporânea. A disciplina proporcionou ambientes de intervenção teórica através de artigos com temas construídos pelos próprios alunos, que tiveram publicações em jornal 
da comunidade. Também, tratou os estudos da corporeidade a partir do próprio profissional do lazer para se ter subsídios de discutir a totalidade do ser de quem se está trabalhando. Tal intervenção teórica teve seu tratamento do conhecimento em sala de aula, perpassando também pelas ações práticas do seu corpo como referência para ações mais eficazes, considerando seu discurso enquanto profissional. Para fundamentar essa prática, reporta-se a Gonçalves (1994), quando afirma que o corpo reduz sua capacidade de percepção sensorial, transformando suas manifestações, sentimentos e expressões em gestos instrumentalizados, para satisfazer o sistema capitalista de produção. Nessa maneira de viver o corpo, o homem reprime as satisfações, desejos, afetos e gratificação, reduzindo-se a um mero espectador de sua própria vida. O mais grave, é a falta de consciência por está vivendo essa relação com o mundo do trabalho e, consequentemente, tendo por certo seu viver cotidiano.

O meu corpo é minha referência diante do mundo, por isso é necessário respeitar suas expressões, seus anseios, desejos, suas limitações. Olhando pelo prisma da prática de atividade física, é vislumbrar a consciência corporal. Nas palavras de Merleau-Ponty (1999): “é verdade que tenho consciência de meu corpo através do mundo, que ele é, no centro do mundo, o termo não-percebido para o qual todos os objetos voltam a sua face, é verdade pela mesma razão que meu corpo é o pivô do mundo: sei que os objetos têm várias faces porque eu poderia fazer a volta em torno deles, e neste sentido tenho consciência do mundo por meio de meu corpo" (p.122). Em outras palavras: "reivindicar a leitura fenomenológica para a educação do fenômeno corpo é falar de uma aprendizagem humana, é aprender de maneira humana a ser homem, a existir como homem. Aí estaremos falando de uma aprendizagem significativa” (Moreira, 1995, p.29). Essa existência como homem, consciente de suas determinações, é capaz de uma praxis transformadora e libertadora.

Na disciplina de TCC I tem três momentos distintos. No primeiro, discute-se o problema a ser investigado e conseqüentemente a construção do projeto de pesquisa para ser encaminhado ao professor-orientador. No segundo, palestras reflexivas sobre os saberes necessários para se buscar a autoformação; e o terceiro, é o momento da qualificação do projeto de pesquisa.

As palestras reflexivas têm sua ênfase no processo educacional do indivíduo, no sujeito coletivo, na aprendizagem, na construção do conhecimento, no desenvolvimento da compreensão, na necessidade de construção e reconstrução do homem e do mundo. Então, a educação, usando ou não as novas instrumentações, deverá estar voltada para o desenvolvimento humano como fator mais importante nesse momento de transição, como argamassa principal de um processo de transformação que não significa apenas uma grande mudança, mas uma transformação radical que afetará cada um de nós e as próximas gerações. Isto porque, sabemos que as nossas decisões pessoais, as nossas escolhas, nossos pensamentos e nossas ações, afetam não apenas o comportamento de cada um, mas também o comportamento dos indivíduos que interagem conosco. E a curto, médio e longo prazos, nossos padrões comportamentais poderão também interferir nos ambientes em que vivemos, na evolução da espécie humana e na própria vida do planeta.

O ser humano para evoluir enquanto espécie busca possuir pelo menos sete distintas inteligências, que são definidas no sentido de formar produtos valorizados na cultura. São elas: lingüística; lógica; espacial; musical; cinestésica; interpessoal e intrapessoal (Gardner, 1999). 
O indivíduo considerado extraordinário faz duas escolhas, consciente ou não. Uma centrada em pessoas ou objetos e a outra investe no aperfeiçoamento das práticas do domínio ou tentam derrubá-las. Reforçando que o domínio precisa do campo de atenção para ter seu reconhecimento. Nas palavras de Gardner (1999, p. 129 - 130):

Um efeito adicional pode ser obtido se estender esta tríade como se segue. O indivíduo é visto como ponto de partida para um núcleo que inclui família e comunidade local; o domínio é visto como o ponto de partida para um núcleo que inclui o âmbito das formas culturais; o campo é visto como o ponto de partida para um módulo que engloba a sociedade mais abrangente. Todos os três núcleos coincidem à medida que se concentram no indivíduo em sua primeira relação com a obra, sendo Sociedade (campo), Cultura (domínio), Obra e indivíduo.

Os alunos que são participantes da pesquisa aderiram a esse projeto de discussão da prática por compreenderem a relevância da construção de saberes a partir das questões do cotidiano como situações problematizadoras, refletindo o momento presente e estando a procura de uma interpretação para aquilo que é vivenciado. Quando o educador faz esta reflexão ao mesmo tempo em que vivência uma determinada situação, acontece a reflexão/ação. Esta etapa permite uma reorientação da ação, no exato momento em que a está a viver. Se esta reflexão se dá após a ação e tem caráter retrospectivo, o professor reflete sobre a ação. Há então um certo distanciamento, um olhar distinto daquele que vivenciou aquela ação (Schön, 1998).

\section{REFERÊNCIAS BIBLIOGRÁFICAS}

BORGES, Cecília. Saberes docentes: diferentes tipologias e classificações de um campo de pesquisa. In Revista Educação e Sociedade, Ano XXII - abril, Campinas, SP, 2001.

SP: Papirus, 1998.

O professor de educação física e a construção do saber. Campinas,

GARDNER, H. Estruturas da mente: A teoria das inteligências múltiplas. Porto Alegre: Artes Médicas Sul. 1994.

Mentes extraordinárias. Perfis de 4 pessoas excepcionais e um estudo sobre o extraordinário em cada um de nós. Rio de Janeiro, RJ: Rocco, 1999.

GONÇALVES, Maria. Sentir, pensar e agir: corporeidade e educação. São Paulo: Papirus, 1994.

MERLEAU-PONTY, Maurice. Fenomenologia da percepção. São Paulo, SP: Martins fontes, 1999.

MORAES, Maria Cândida. O Paradigma Educacional Emergente. Ed. Papirus; 1997.

MOREIRA, W. Corpo pressente. São Paulo, SP:Papirus, 1995.

MORIN, Edgar. O método 2. A vida da vida. Porto Alegre, RS: Sulina, 2002.

Os sete saberes necessários à educação do futuro. São Paulo, SP:

Cortez, 2003.

. O método 5. A humanidade da humanidade. A identidade humana.

Porto Alegre: Sulina, 2002.

PETRAGLIA, Izabel Cristina. Edgar Morin. A educação e a complexidade do ser e do saber. Petrópolis, RJ: Vozes, 1995.

SANTIN, Silvino. Educação fisíca: uma abordagem filosófica da corporeidade. Ijuí, RS: Unijuí ed., 1987. 
MAIA, S. C. F. e CAVALCANTI, K. B.

SCHÖN, D. Formar professores como profissionais reflexivos. In: NÓVOA, A Os professores e sua formação. Lisboa: Dom Quixote, 1998. 